\title{
Volatility Dynamics in Foreign Exchange Rates: Further Evidence from Malaysian Ringgit and Singapore Dollar
}

\author{
${ }^{1}$ Kin-Yip Ho and ${ }^{2}$ Albert K. Tsui \\ ${ }^{1}$ Department of Economics, Cornell University Ithaca, NY 14853, USA, ${ }^{2}$ Department of Economics, \\ National University of Singapore, Singapore 117570 Email: $\underline{k h 267 @ \text { cornell.edu }}$
}

Keywords: Exchange rate volatility; Fractional integration; Long memory; Bivariate asymmetric GARCH; Varying conditional correlations

\section{EXTENDED ABSTRACT}

The volatility dynamics of foreign exchanges have been the focus of research since Bollerslev's (1986) seminal work on the generalized autoregressive conditional heteroscedasticity $(\mathrm{GARCH})$ modelling. Several well-established empirical regularities may be highlighted as follows: [a] evidence of volatility clustering is detected in the exchange rates returns; [b] asymmetric effects in exchange rate volatility are not common; and [c] exchange rate volatility may display significant persistence and dependence between observations. Among others, Franses and van Dijk (2000) provide an in-depth review of this subject and illustrate the importance of capturing conditional variance using GARCH-type models in the empirical finance research.

In this paper we follow up the study of the Malaysian ringgit and the Singapore dollar in the Asia-Pacific markets by Tse and Tsui (1997). A family of bivariate GARCH-type models with time-varying correlations is proposed to analyse the volatility dynamics of the Malaysian ringgit and the Singapore dollar, respectively. The proposed models can capture stylized features of long-memory, asymmetric conditional volatility, and time-varying correlations simultaneously in returns of the two currencies. They not only retain the flexibility and intuition of the univariate GARCH structure but also satisfy the positive-definite condition of the conditional variance and covariance matrix.

The fractionally integrated models are able to distinguish between long persistence and exponential decay in the impact of exchange rate volatilities. We also examine the robustness of the volatility dynamics of the two currencies against the Japanese yen as the alternative numeraire currency besides the dollar. This may provide bearing for the market practitioners to formulate their currency hedging strategies.

Consistent with results of Tse and Tsui (1997) and Tsui and Ho (2004), we do not find support of asymmetric volatility when these currencies are measured against the dollar. But we find strong evidence of negative asymmetric effects for the Singapore dollar when it is measured against the yen. Additionally, we detect significant evidence of extreme persistence in the impacts of foreign exchange shocks, regardless of the choice of the numeraire currency and the volatility structure. It seems that the impacts of exchange rate shocks display much longer persistence than the standard exponential decay.

Moreover, the likelihood ratio tests indicate that the bivariate fractionally integrated models generally outperform those models without the long-memory structure. Furthermore, we find relatively weaker evidence of time-varying correlations when the Malaysian ringgit and the Singapore dollar are measured against the dollar. However, we detect significant support of time-varying correlations when these currencies are measured against the yen. It maps out an interesting time path of the conditional correlations between the Malaysian ringgit and the Singapore dollar. 


\section{Introduction}

The volatility dynamics of foreign exchanges have been the focus of research since Bollerslev's (1986) seminal work on the generalized autoregressive conditional heteroscedasticity (GARCH) modelling. Several well-established empirical regularities may be highlighted as follows: [a] evidence of volatility clustering is detected in the exchange rates returns; [b] asymmetric effects in exchange rate volatility are not common; and [c] exchange rate volatility may display significant persistence and dependence between observations. Among others, Franses and van Dijk (2000) provide an in-depth review of this subject and illustrate the importance of capturing conditional variance using GARCH-type models in the empirical finance research.

In this paper we follow up the study of the Malaysian ringgit and the Singapore dollar in the Asia-Pacific markets by Tse and Tsui (1997). To ensure consistency in comparison, we confine our investigation to the GARCH-type models. Instead of using univariate APARCH models by Tse and Tsui (1997), we propose a family of bivariate MGARCH models to concurrently capture the stylized features of volatility asymmetry, long-range persistence in volatility, and time-varying correlations. The proposed models automatically ensure the positive definiteness of the conditional variance-covariance matrix once convergence is obtained. The parameter estimates are relatively easy to interpret, as the univariate GARCH-type equations are retained. Unlike Bollerslev's (1990) constant correlation MGARCH model, the time-varying conditional correlations models are able to map out the time-path of conditional correlations between the currencies. In addition, we investigate the behaviour of longmemory persistence in volatility of the Malaysian ringgit and the Sinagapore dollar using fractionally integrated GARCH-type models. These models help to distinguish between long persistence and exponential decay in the impacts of exchange rate volatilities. Moreover, we study the robustness of the volatility dynamics of the two currencies against the Japanese yen as the alternative numeraire currency besides the dollar. This may help the market practitioners to formulate their currency hedging strategies.

The rest of the paper is organized as follows. Section 2 presents the methodology of synthesizing features of volatility asymmetry, long-memory and timevarying correlations in a bivariate GARCH-type framework. Section 3 briefly describes the data sets used and the estimation results. Section 4 provides some concluding remarks.

\section{Methodology}

We highlight the gist of the bivariate $\operatorname{GARCH}(1,1)$ model with time-varying conditional correlations (VC-GARCH) proposed by Tse and Tsui (2002). Then we incorporate two structures of asymmetric volatility and long memory into the conditional variance equations so as to synthesize the bivariate GARCH-type models.

Let $\mathrm{y}_{\mathrm{t}}=\left(\mathrm{y}_{1 \mathrm{t}}, \mathrm{y}_{2 \mathrm{t}}\right)^{\prime}$ be the bivariate vector of variables with time-varying variance-covariance matrix $\mathrm{H}_{t}$, and let $\mu_{\mathrm{it}}\left(\xi_{\mathrm{i}}\right)$ be the arbitrary conditional mean functions which depend on $\xi_{\mathrm{i}}$, a column vector of parameters. A typical bivariate $\operatorname{GARCH}(1,1)$ model can be specified as follows:

$y_{i t}=\mu_{i t}\left(\xi_{i}\right)+\varepsilon_{i t}, \quad i=1,2$

where $\left(\varepsilon_{1 t}, \varepsilon_{2 t}\right)^{\prime} \mid \Phi_{t-1} \sim\left(O, H_{t}\right)$

Note that $\Phi_{\mathrm{t}}$ is the $\sigma$-algebra generated by all the available information up to time t. The random disturbance terms $\varepsilon_{\text {it }}$ and the conditional variance equations $h_{\text {iit }}$ are modelled as follows:

$\varepsilon_{i t}=\sqrt{h_{i i t}} e_{i t}, \quad$ where $e_{i t} \sim N(0,1)$

$h_{i i t}=\eta_{i}+\alpha_{i} \varepsilon_{i t-1}^{2}+\beta_{i} h_{i i t-1}$

where (4) is the standard Bollerslev's (1986) symmetric GARCH $(1,1)$ model.

Denote the $i j$-th element $(i, j=1,2)$ in $H_{t}$ by $h_{i j t}$. The conditional correlation coefficients can be defined as $\rho_{i j t}=\frac{h_{i j t}}{\sqrt{h_{i i t} h_{j j t}}}$. Tse and Tsui (2002) assume that the time-varying conditional correlation matrix $\Gamma_{t}=\left\{\rho_{i j t}\right\}$ is generated by the following recursion

$\rho_{12 t}=\left(1-\pi_{1}-\pi_{2}\right) \rho_{12}+\pi_{1} \rho_{12, t-1}+\pi_{2} \psi_{12, t-1}$

$\psi_{12, t-1}=\frac{\sum_{a=1}^{2} e_{1, t-a} e_{2, t-a}}{\sqrt{\left(\sum_{a=1}^{2} e_{1, t-a}^{2}\right)\left(\sum_{a=1}^{2} e_{2, t-a}^{2}\right)}}$ 
$l_{t}(\theta)=-\frac{1}{2} \sum_{i=1}^{2} \log h_{i i t}-\frac{1}{2} \log \left(1-\rho_{12 t}^{2}\right)-\frac{e_{1 t}^{2}+e_{2 t}^{2}-2 \rho_{12 t} e_{1 t} e_{2 t}}{2\left(1-\rho_{12 t}^{2}\right)}$

The conditional correlation in (5) inherits the prototype properties of $\operatorname{GARCH}(1,1)$ structure. When $\pi_{1}$ and $\pi_{2}$ are zeros, the conditional correlation equation in (5) is reduced to Bollerslev's (1990) constant-correlation structure (CC-GARCH). The likelihood ratio test can be readily applied to compare the performance of both models.

The structures of asymmetric volatility and long memory dynamics are to be incorporated into the VC-GARCH model by modifying the symmetric conditional variance equation in (4). To maintain consistency in comparison, we choose two wellestablished asymmetric structures among the GARCH-type models. They include: the asymmetric GARCH $(1,1)$ (AGARCH $(1,1))$ model proposed by Engle (1990) and the asymmetric power $\operatorname{ARCH}(1,1)$ (APARCH $(1,1)$ ) model of Ding, Granger, and Engle (1993), respectively. Indeed, Tse and Tsui (1997) use the APARCH $(1,1)$ model to capture the possibly asymmetric effects of exchange shocks on future volatilities. In addition, these asymmetric GARCHtype models are less restrictive in assumptions and are more flexible to accommodate alternative variations. Their main features are briefly summarized as follows:

[a] Engle's (1990) asymmetric $\operatorname{GARCH}(1,1)$ (AGARCH(1,1)) model:

$h_{i i t}=\omega_{i}+\alpha_{i}\left(\varepsilon_{i t-1}-\gamma_{i}\right)^{2}+\beta_{i} h_{i i t-1}$

where $\gamma_{\mathrm{i}}$ is the asymmetric coefficient.

[b] Ding, Granger, and Engle's (1993) asymmetric power ARCH(1,1) (APARCH $(1,1))$ model.

$h_{i i t}^{\delta_{i} / 2}=\eta_{i}+\alpha_{i}\left(\left|\varepsilon_{i t-1}\right|-\gamma_{i} \varepsilon_{i t-1}\right)^{\delta_{i}}+\beta_{i} h_{i i t-1}^{\delta_{i} / 2}$

where $\gamma_{i}$ is the asymmetric coefficient. We note in passing that although the APARCH structure nests 7 models together (see Ding, Granger, and Engle (1993) for details), it does not nest the AGARCH model.

Turning to the structure of long-memory dynamics in volatility, we may transform the conditional variance equations in (4), (8) and (9) so that they are fractionally integrated. We follow the methodology by Baillie, Bollerslev, and Mikkelsen (BBM) (1996). Below is a summary of the conditional variance equations for three fractionally integrated (FI)
GARCH-type models obtained by the BBM approach.

[a]Fractionally integrated $\operatorname{GARCH}(1,1)$ model (FIGARCH $(1, \mathrm{~d}, 1))$

$h_{i i t}=\frac{\eta_{i}}{1-\beta_{i}}+\lambda_{i}(L) \varepsilon_{i t}^{2}$

where

$\lambda_{i}(L)=\sum_{a=1}^{\infty} \lambda_{i a} L^{a}=1-\left(1-\beta_{i} L\right)^{-1}\left(1-\phi_{i} L\right)(1-L)^{d_{i}}$.

[b] Fractionally integrated asymmetric $\operatorname{GARCH}(1,1)$ model $(($ FIAGARCH $)(1, \mathrm{~d})$,$) model$

$h_{i i t}=\frac{\omega_{i}}{1-\beta_{i}}+\lambda_{i}(L)\left(\varepsilon_{i t}-\gamma_{i}\right)^{2}$

where $\lambda_{i}(L)$ is defined as in (10).

Note that (11) is similar to the $\operatorname{FIGARCH}(1, \mathrm{~d}, 1)$ model in (10), except that it allows past return shocks to have asymmetric effects on the conditional volatility.

[c] Fractionally integrated $\operatorname{APARCH}(1,1)$ model (FIAPARCH $(1, \mathrm{~d}, 1)$ )

$h_{i i t}^{\delta_{i} / 2}=\frac{\eta_{i}}{1-\beta_{i}}+\lambda_{i}(L)\left(\left|\varepsilon_{i t}\right|-\gamma_{i} \varepsilon_{i t}\right)^{\delta_{i}}$

where $\lambda_{i}(L)$ is defined as in (10). Similar to the FIAGARCH(1,d,1) model in (11), (12) allows past shocks to have asymmetric effects on the conditional volatility. Details of the derivations are given in Tsui and Ho (2004).

All parameters of GARCH-type models can be estimated using Bollerslev-Wooldridge's (1992) quasi-maximum likelihood estimation (QMLE) approach. Appropriate assumptions for the start-up conditions are made to facilitate convergence of the QMLE optimization process. These include the computation of $\lambda_{i}(L)$, the number of lags, and the initial values. For instance, the response coefficients for each of the fractionally integrated GARCH-type models

$$
\lambda_{i}(L)=\sum_{a=1}^{\infty} \lambda_{i a} L^{a}=1-\left(1-\beta_{i} L\right)^{-1}\left(1-\phi_{i} L\right)(1-L)^{d_{i}}
$$

are obtained by adopting the following infinite recursions given in Bollerslev and Mikkelsen (1996):

$\lambda_{i 1}=\phi_{i}-\beta_{i}+d_{i}$,

$\lambda_{i b}=\beta_{i} \lambda_{i b-1}+\left[\left(b-1-d_{i}\right) / b-\phi_{i}\right] \zeta_{i b-1}, \quad b=2, \ldots, \infty$

where $\zeta_{i b}=\zeta_{i b-1}\left(b-1-d_{i}\right) / b$, with $\zeta_{i 1}=d_{i}$ 
As can be observed from (13), when $b$ approaches infinity, an adequate finite truncation is necessary to secure the long-memory dynamics. The parameter estimates trimmed at 1000 lags are reasonably close to those trimmed at 2000 lags. To save the computational time, we truncate $\lambda_{i}(L)$ after the first 1000 lags.

We shall investigate 6 different model specifications, including 3 basic symmetric and asymmetric GARCH-type models and their extensions to the corresponding fractionally integrated GARCH-type models. We then apply these univariate models individually to the Malaysian ringgit and the Singapore dollar against the dollar or the yen, thereby obtaining 6 bivariate CC-MGARCH-type models and 6 bivariate VC-MGARCH-type models, respectively.

\section{Data and Estimation Results}

Our data sets consist of 2998 daily observations of the Malaysian ringgit (MYR) and the Singapore dollar (SGD), covering the period from 2 January 1986 to 30 June 1997. More recent observations are excluded to avoid the possible distortions caused by the outbreak of the 2-year Asian financial crisis since July 1997. The exchange rates against the US dollar (USD) are obtained directly from DataStream International and details of these series are discussed in Tsui and Ho (2004). Owing to the nonavailability of the bilateral Japanese yen (JPY) exchange rates for the period under study, we utilize the implied cross rates instead. They are obtained by dividing the exchange rate of a nation's currency against the US dollar with the Japanese yen-US dollar (JPY/USD) exchange rate.

Table 1. Summary Statistics of Exchange Rates \begin{tabular}{|l|l|l|l|l|}
\hline Variable & MYR/JPY & SGD/JPY & MYR/USD & SGD/USD \\
\hline
\end{tabular} Panel A: Moments, Maximum and Minimum

\begin{tabular}{|l|l|l|l|l|}
\hline Mean & 0.0198 & 0.0053 & 0.0015 & -0.0130 \\
\hline Median & 0.0000 & -0.0058 & 0.0000 & 0.0000 \\
\hline Maximum & 4.9830 & 4.6842 & 2.3736 & 2.0232 \\
\hline Minimum & -3.9626 & -3.8903 & -2.9363 & -2.2501 \\
\hline Std. Dev. & 0.6822 & 0.6340 & 0.2555 & 0.2538 \\
\hline Skewness & 0.4145 & 0.3571 & -0.2254 & -0.3627 \\
\hline Kurtosis & 6.9749 & 6.6848 & 24.1763 & 10.3654 \\
\hline Size & 2997 & 2997 & 2997 & 2997 \\
\hline Panel B: Ljung-Box Q-statistic \\
\hline 5 lags & 9.1017 & 10.6973 & 49.1369 & 68.9244 \\
\hline 10 lags & 40.4815 & 37.4101 & 88.6244 & 79.6134 \\
\hline Panel C: Runs Test & \\
\hline $\mathrm{R}_{1}$ & 3.8623 & 2.9018 & 0.4672 & 3.3028 \\
\hline $\mathrm{R}_{2}-5.3707$ & -5.0340 & -8.4397 & -7.9397 \\
\hline $\mathrm{R}_{3}$ & -4.2167 & -2.1550 & -10.5792 & -7.6008 \\
\hline
\end{tabular}

Notes:

$\mathrm{JPY}=$ Japanese Yen, MYR $=$ Malaysian ringgit, SGD $=$ Singapore dollar, USD = US dollar; For the Runs Test, $\mathrm{R}_{\mathrm{i}}$ for $i=1,2,3$ denote the runs tests of the series $R_{t},\left|R_{t}\right|$, and $\mathrm{R}_{\mathrm{t}}{ }^{2}$ respectively. Under the null hypothesis that successive observations in the series are independent, the test statistic is asymptotically standard normal.

The daily nominal exchange rate returns expressed in percentage are computed on a continuously compounding basis as:

$$
y_{t}=\log \left(\frac{S_{t}}{S_{t-1}}\right) \times 100
$$

where $S_{t}$ is the daily exchange rate. We assume that the conditional mean equation is captured by an $\operatorname{AR}(p)$ filter:

$$
y_{i t}=\xi_{0}+\sum_{a=1}^{p} \xi_{\text {iat }} y_{i t-a}+\varepsilon_{i t}, i=1,2
$$

Table 1 provides a summary of the descriptive statistics of $y_{t}$ for the two currencies measured against the dollar or the yen. For a standard normal distribution, the skewness and kurtosis have values of 0 and 3, respectively. As can be observed from Panel A of Table 1, all differenced logarithmic series have kurtosis greater than 3. In particular, the MYR and SGD exhibit much higher kurtosis when they are measured against the dollar.

Though not reported here, the augmented DickeyFuller and Phillips-Perron tests are all insignificant at the 5\% level, thereby indicating that the return series of the MYR and SGD are stationary. However, the Ljung-Box Q-statistics and the BDS test statistics (Brock, Dechert, and Scheinkman (1996)) suggest that both foreign exchange series are not independently and identically distributed. In addition, the highly significant $\mathrm{ARCH}$ and the runs test consistently indicate the presence of conditional heteroscedasticity in the return series. As such, the GARCH-type modelling of the volatility structures may be appropriate.

The QMLE approach provides consistent estimators even for non-normal errors with a thick-tailed distribution. For the mean equation, we find that the parsimonious $\mathrm{AR}(1)$ model is a reasonably adequate filter, taking into consideration of the log-likelihood values and the residual checks. To save space, we report only estimates of the conditional variance and correlation equations from the following models: the VC-GARCH, VC-AGARCH, VC-APARCH, VCFIGARCH, VC-FIAGARCH and VC-FIAPARCH, respectively. Most of the parameter estimates from 
the constant-correlation models are omitted. The complete set of estimation results is available upon request.

Tables 2-7 summarize the QMLE of the parameters of the bivariate VC-GARCH, VC-APARCH, VCAGARCH, VC-FIGARCH, VC-FIAPARCH and VC-FIAGARCH models, respectively. We first discuss the evidence of asymmetric volatility. For the currencies against the dollar, only the Malaysian ringgit exhibits asymmetric volatility under the VCFIAPGARCH model, whereas there is no evidence of asymmetric effects for the SGD. Our results are consistent with the findings by Tse and Tsui (1997), and Tsui and Ho (2004), respectively. In contrast, when the yen is used as the numeraire currency, we detect significant evidence of negative asymmetric volatility for the SGD based on all of the GARCHtype models. As for the MYR, except for the VCAGARCH model, we do not detect evidence of asymmetric volatility. Our findings have policy implications for the engineering of currency hedging strategies and international investment portfolios.

Turning to fractional differencing GARCH-type models, we observe that all the estimates are statistically significantly different from 0 and 1 . This indicates that the impact of shocks to the conditional volatility displays a hyperbolic rather than exponential rate of decay. Our result is robust to the choice of the numeraire currency and the models. Second, most of the fractional differencing parameters for the MYR and the SGD are similar across the GARCH-type models for a given numeraire currency. For example, when the dollar is used as the numeraire, the estimated values of $d$ for MYR and SGD are 0.4583 and 0.4428 respectively for the symmetric VC-FIGARCH model; 0.4217 and 0.5690 for the asymmetric VC-FIAPARCH model; and 0.4497 and 0.4470 for the asymmetric VCFIAGARCH model, respectively. Similarly, when the yen is used as the numeraire currency, the MYR and the SGD have consistently lower estimated values for $d$ within the range of $0.20-0.30$ than that of the corresponding GARCH-type counterparts under the dollar. Moreover, the likelihood ratio test statistics are all significant at the 5\% level, thereby indicating that the fractionally integrated models are more adequate than those without the long memory structure.

To assess the correlation dynamics of the two currencies, we apply the likelihood ratio (LR) test to the null hypothesis of $\pi_{1}=\pi_{2}=0$ (see equation (5)). The LR test statistics follows an asymptotic chi- squared distribution with two degrees of freedom. As can be gleaned from columns 8-13 of Tables 2-7, all the LR tests indicate that the null hypothesis of constant conditional correlations is rejected at the $5 \%$ level of significance, thereby suggesting that the conditional correlations are time-varying. Such findings are robust across models. In contrast, almost all of the individual estimates of $\pi_{1}$ and $\pi_{2}$ are statistically insignificant when the MYR and SGD are measured against the dollar; and all individual estimates are significant at the 5\% level when their exchange rates are based on the yen. This implies that the evidence of time-varying correlations between MYR/USD and SGD/USD is relatively weaker, and it is consistent with Tse's (2000) conclusion that the hypothesis of constant conditional correlation cannot be rejected for the MYR and SGD. However, we detect strong support of time-varying correlations between MYR and SGD when the Japanese yen is used as the numeraire currency. The reason as to why the asymmetric effects are not robust to exchange rates under different numeriare currency is still unknown to researchers.

Another noteworthy finding is that the magnitude of the time-variant component of the correlation equation is much higher when the Japanese yen is the numeraire. For example, the estimated correlations of the MYR/USD and SGD/USD (MYR/JPY and SGD/JPY) based on the VCGARCH, VC-APARCH, VC-AGARCH, VCFIGARCH, VC-FIAPARCH and VC-FIAGARCH models are 0.3784 (0.9408), 0.3784 (0.9408), 0.3778 (0.9400), 0.3920 (0.9409), 0.3856 (0.9398) and $0.3915(0.9394)$; respectively. This also applies to the corresponding estimates for the CC-GARCH, CC-APARCH, CC-AGARCH, CC-FIGARCH, CCFIAPARCH and CC-FIAGARCH models. They are: 0.3591 (0.9044), 0.3585 (0.9045), 0.3587 (0.9041), $0.3694(0.9058), 0.3644(0.9056)$ and 0.3692 (0.9053), respectively. Moreover, it can be seen that all estimates of the constant components of the conditional correlations are significant at the 5\% level.

Finally, we perform residual diagnostics for all the models. Most of the Ljung-Box Q-statistics and McLeod-Li test statistics of the standardized residuals are insignificant at the $5 \%$ levels. However, the BDS test statistics for the bivariate VC-APARCH model are still significant at the 5\% level, suggesting that dependencies are still present for the MYR/JPY and SGD/JPY series. But the BDS tests are less significant for residuals of the 
same series in the VC-FIAPARCH model. Apparently, the fractionally integrated model acts as a better variance filter than those without such a structure. Moreover, most of the Ljung-Box Qstatistics based on the cross product of the standardised residuals are insignificant at the 5\% level, thereby suggesting the absence of serial correlation. However, the time-varying models are preferred to the constant-correlation models as there is less evidence of serial correlation in the cross product of the standardised residuals. The complete test results are available from the authors upon request.

\section{Concluding Remarks}

We have investigated the empirical evidence of asymmetric volatility and long memory of the Malaysian ringgit and the Singapore dollar in the Asia-Pacific markets using bivariate GARCH-type models.

Consistent with previous studies by Hsieh (1993), Tse and Tsui (1997), and Tsui and Ho (2004), we find that returns of the Malaysian ringgit and the Singapore dollar against the dollar do not exhibit asymmetric effects in their conditional volatilities. In contrast, we detect strong evidence of negative asymmetric volatility when the Singapore dollar is measured against the yen. This may imply an unbalanced degree of uncertainty induced by depreciation and appreciation of the Singapore dollar against the yen in the market. In addition, we detect evidence of long-range temporal dependence in volatility in the two currencies, regardless of the choice of the numeraire currency. It seems that the impacts of exchange rate shocks display much longer persistence than the standard exponential decay. Based on the log-likelihood values, we find that the bivariate fractionally integrated models generally outperform those models without the long-range dependent structures in the conditional variance. Moreover, we find significant evidence of timevarying conditional correlations in the two currencies against the yen. In contrast, the evidence of timevarying correlations among the bilateral USD rates is much weaker. The time-varying models help to map out interesting time paths of the correlation between the Malaysian ringgit and the Singapore dollar.

\section{References}

Baillie, R., Bollerslev, T., and Mikkelsen, H. (1996). 'Fractionally Integrated Generalised Autoregressive Conditional
Heteroskedasticity.' Journal of Econometrics 74, 3-30.

Bollerslev, T. (1986). 'Generalised Autoregressive Conditional Heteroskedasticity.' Journal of Econometrics 31, 207-327.

Bollerslev, T. (1990). 'Modelling the Coherence in Short-run Nominal Exchange Rates: A Multivariate Generalised ARCH Model.' Review of Economics and Statistics 72, 498505.

Bollerslev, T., and Wooldridge, J.M. (1992). 'QuasiMaximum Likelihood Estimation and Inference in Dynamic Models with TimeVarying Covariances', Econometric Reviews 11, 143-72.

Blake LeBaron (1996). 'A Test for Independence Based on the Correlation Dimension.' Econometric Reviews 15, 197-235.

Ding, Z., Granger, C., and Engle, R.F. (1993). 'A Long-memory Property of Stock Market Returns and a New Model', Journal of Empirical Finance 1, 107-131.

Engle, R.F. (1982). 'Autoregressive Conditional Heteroskedasticity with Estimates of the Variance of the U.K. Inflation', Econometrica 50, 987-1008.

Franses, P.H., and van D. Dijk, van D. (2000). Nonlinear time series models in empirical finance, Cambridge.

Hsieh, D.A. (1993). 'Implications of Nonlinear Dynamics for Financial Risk Management', Journal of Financial and Quantitative Analysis 28, 41-64.

Tse, Y.K. (2000). 'A Test for Constant Correlations in a Multivariate GARCH Model', Journal of Econometrics 98, 107-127.

Tse, Y.K., and Tsui A.K. (1997). 'Conditional Volatility in Foreign Exchange Rates: Evidence from the Malaysian Ringgit and Singapore Dollar.' Pacific Basin Finance Journal 5, 345-356.

Tse, Y.K., and Tsui, A.K. (2002). 'A Multivariate Generalised Autoregressive Conditional 
Heteroskedasticity Model with Time-Varying Correlations', Journal of Business and Economic Statistics 20, 351-362.
Results Based on the Fractionally Integrated Approach.' Journal of Applied Econometrics 19, 637-642.

Tsui, A.K. and Ho, K.Y. (2004). 'Conditional Heteroscedasticity of Exchange Rates: Further

Table 2 Estimation Results of VC-GARCH(1,1) Model: $h_{t}=\eta+\alpha \varepsilon_{t-1}^{2}+\beta h_{t-1} ; \Gamma_{t}=\left(1-\pi_{1}-\pi_{2}\right) \Gamma+\pi_{1} \Gamma_{t-1}+\pi_{2} \Psi_{t-1}$

\begin{tabular}{|c|c|c|c|c|c|c|c|c|c|c|}
\hline Variable & $\eta$ & $\beta$ & $\alpha$ & $\Gamma$ & $\pi_{1}$ & $\pi_{2}$ & LL (VC) & Corr (CC) & LL (CC) & LR \\
\hline $\begin{array}{l}\text { MYR/USD } \\
\end{array}$ & $\begin{array}{l}0.0031 \\
(0.0012)\end{array}$ & $\begin{array}{l}0.7872 \\
(0.0453)\end{array}$ & $\begin{array}{l}0.1705 \\
(0.0349)\end{array}$ & \multirow[t]{2}{*}{$\begin{array}{l}0.3782 \\
(0.0263)\end{array}$} & \multirow[t]{2}{*}{$\begin{array}{l}0.4309 \\
(0.7034)\end{array}$} & \multirow[t]{2}{*}{$\begin{array}{l}0.1129 \\
(0.0744)\end{array}$} & \multirow[t]{2}{*}{6327} & \multirow[t]{2}{*}{$\begin{array}{l}0.3591 \\
(0.0229)\end{array}$} & \multirow[t]{2}{*}{6305} & \multirow[t]{2}{*}{443.74} \\
\hline SGD/USD & $\begin{array}{l}0.0029 \\
(0.0016) \\
\end{array}$ & $\begin{array}{l}0.8595 \\
(0.0562) \\
\end{array}$ & $\begin{array}{l}0.1011 \\
(0.0381) \\
\end{array}$ & & & & & & & \\
\hline "MYR/JPY & $\begin{array}{l}0.0186 \\
(0.0236) \\
\end{array}$ & $\begin{array}{l}0.9013 \\
(0.0952)\end{array}$ & $\begin{array}{l}0.0601 \\
(0.0502) \\
\end{array}$ & \multirow[t]{2}{*}{$\begin{array}{l}0.9408 \\
(0.0087)\end{array}$} & \multirow[t]{2}{*}{$\begin{array}{l}0.8715 \\
(0.0363)\end{array}$} & \multirow[t]{2}{*}{$\begin{array}{l}0.0351 \\
(0.0077)\end{array}$} & \multirow[t]{2}{*}{2372} & \multirow[t]{2}{*}{$\begin{array}{l}0.9044 \\
(0.9044)\end{array}$} & \multirow[t]{2}{*}{2214} & \multirow[t]{2}{*}{315.60} \\
\hline SGD/JPY & $\begin{array}{l}0.0147 \\
(0.0133)\end{array}$ & $\begin{array}{l}0.9113 \\
(0.0586)\end{array}$ & $\begin{array}{l}0.0540 \\
(0.0293)\end{array}$ & & & & & & & \\
\hline
\end{tabular}

Notes:

1. All standard errors (in parenthesis) are the heteroskedastic-consistent Bollerslev-Wooldridge standard errors computed based on the Quasi-Maximum Likelihood Estimation (QMLE) technique.

2. Log-likelihood value (VC) and Log-likelihood value (CC) refer to the likelihood values obtained from the VC$\operatorname{GARCH}(1,1)$ and $\mathrm{CC}-\mathrm{GARCH}(1,1)$ models respectively.

3. Correlations (CC) refer to the conditional correlation coefficient obtained from the CC-GARCH $(1,1)$ model.

4. LR is the likelihood ratio statistic for $\mathrm{H}_{0}: \pi_{1}=\pi_{2}=0$ in the VC-GARCH(1,1) model. It is distributed as chisquared with 2 degrees of freedom under $\mathrm{H}_{0}$.

Table 3 Estimation Results of VC-APARCH(1,1) Model: $h_{t}^{\delta / 2}=\eta+\alpha\left(\left|\varepsilon_{t-1}\right|-\gamma \varepsilon_{t-1}\right)^{\delta}+\beta h^{\delta / 2}{ }_{t-1} ; \Gamma_{t}=\left(1-\pi_{1}-\pi_{2}\right) \Gamma+$ $\pi_{1} \Gamma_{\mathrm{t}-1}+\pi_{2} \Psi_{\mathrm{t}-1}$

\begin{tabular}{|c|c|c|c|c|c|c|c|c|c|c|c|c|}
\hline Variable & $\eta$ & $\beta$ & $\alpha$ & $\gamma$ & $\delta$ & $\Gamma$ & $\pi_{1}$ & $\pi_{2}$ & LL (VC) & Corr (CC) & LL (CC) & LR \\
\hline IMYR/USD & $\begin{array}{l}0.0035 \\
(0.002)\end{array}$ & $\begin{array}{l}0.8010 \\
(0.0470)\end{array}$ & $\begin{array}{l}0.1627 \\
(0.0358)\end{array}$ & $\begin{array}{l}-0.1106 \\
(0.0656)\end{array}$ & $\begin{array}{l}1.8861 \\
(0.2646)\end{array}$ & \multirow[t]{2}{*}{$\begin{array}{l}0.3784 \\
(0.026)\end{array}$} & \multirow[t]{2}{*}{$\begin{array}{l}0.4815 \\
(0.915)\end{array}$} & \multirow[t]{2}{*}{$\begin{array}{l}0.1069 \\
(0.100)\end{array}$} & \multirow[t]{2}{*}{6338} & \multirow[t]{2}{*}{$\begin{array}{l}0.3585 \\
(0.0228)\end{array}$} & \multirow[t]{2}{*}{6316} & \multirow[t]{2}{*}{43.4} \\
\hline SGD/USD & $\begin{array}{l}0.0075 \\
(0.005) \\
\end{array}$ & $\begin{array}{l}0.8619 \\
(0.0512)\end{array}$ & $\begin{array}{l}0.1178 \\
(0.0359)\end{array}$ & $\begin{array}{l}0.0176 \\
(0.0921) \\
\end{array}$ & $\begin{array}{l}1.3827 \\
(0.3099) \\
\end{array}$ & & & & & & & \\
\hline MYR/JPY & $\begin{array}{l}0.0287 \\
(0.025)\end{array}$ & $\begin{array}{l}0.9031 \\
(0.0659)\end{array}$ & $\begin{array}{l}0.0713 \\
(0.0377)\end{array}$ & $\begin{array}{l}-0.1943 \\
(0.1117)\end{array}$ & $\begin{array}{l}1.1206 \\
(0.2053)\end{array}$ & \multirow[t]{2}{*}{$\begin{array}{l}0.9408 \\
(0.008)\end{array}$} & \multirow[t]{2}{*}{$\begin{array}{l}0.8670 \\
(0.038)\end{array}$} & \multirow[t]{2}{*}{$\begin{array}{l}0.0356 \\
(0.008)\end{array}$} & \multirow[t]{2}{*}{2394} & \multirow[t]{2}{*}{$\begin{array}{l}0.9045 \\
(0.0065)\end{array}$} & \multirow[t]{2}{*}{2237} & \multirow[t]{2}{*}{314.7} \\
\hline SGD/JPY & $\begin{array}{l}0.0244 \\
(0.016)\end{array}$ & $\begin{array}{l}0.9123 \\
(0.0425)\end{array}$ & $\begin{array}{l}0.0646 \\
(0.0235)\end{array}$ & $\begin{array}{l}-0.2139 \\
(0.1132)\end{array}$ & $\begin{array}{l}1.1065 \\
(0.1713)\end{array}$ & & & & & & & \\
\hline
\end{tabular}

Notes: See notes to Table 2.

Table 4 Estimation Results of VC-AGARCH(1,1) Model: $h_{t}=\eta+\alpha\left(\varepsilon_{t-1}-\gamma\right)^{2}+\beta h_{t-1} ; \Gamma_{t}=\left(1-\pi_{1}-\pi_{2}\right) \Gamma+\pi_{1} \Gamma_{t-1}+$ $\pi_{2} \Psi_{t-1}$

\begin{tabular}{|c|c|c|c|c|c|c|c|c|c|c|c|}
\hline Variable & $\eta$ & $\beta$ & $\alpha$ & $\gamma$ & $\Gamma$ & $\pi_{1}$ & $\pi_{2}$ & LL (VC) & Corr (CC) & LL (CC) & LR \\
\hline MYR/USD & $\begin{array}{l}0.0030 \\
(0.0013)\end{array}$ & $\begin{array}{l}0.7900 \\
(0.0459)\end{array}$ & $\begin{array}{l}0.1670 \\
(0.0355)\end{array}$ & $\begin{array}{l}0.0136 \\
(0.0236)\end{array}$ & \multirow[t]{2}{*}{$\begin{array}{l}0.3778 \\
(0.026)\end{array}$} & \multirow[t]{2}{*}{$\begin{array}{l}0.4186 \\
(0.699)\end{array}$} & \multirow[t]{2}{*}{$\begin{array}{l}0.1139 \\
(0.073)\end{array}$} & \multirow[t]{2}{*}{6329} & \multirow[t]{2}{*}{$\begin{array}{l}0.3587 \\
(0.0227)\end{array}$} & \multirow[t]{2}{*}{6307} & \multirow[t]{2}{*}{43.6} \\
\hline SGD/USD & $\begin{array}{l}0.0027 \\
(0.0015) \\
\end{array}$ & $\begin{array}{l}0.8638 \\
(0.0535) \\
\end{array}$ & $\begin{array}{l}0.0997 \\
(0.0367) \\
\end{array}$ & $\begin{array}{l}-0.0225 \\
(0.0306) \\
\end{array}$ & & & & & & & \\
\hline MYR/JPY & $\begin{array}{l}0.0154 \\
(0.0154)\end{array}$ & $\begin{array}{l}0.9132 \\
(0.0653)\end{array}$ & $\begin{array}{l}0.0513 \\
(0.0341)\end{array}$ & $\begin{array}{l}0.1537 \\
(0.0770)\end{array}$ & \multirow[t]{2}{*}{$\begin{array}{l}0.9400 \\
(0.009)\end{array}$} & \multirow[t]{2}{*}{$\begin{array}{l}0.8708 \\
(0.036)\end{array}$} & \multirow[t]{2}{*}{$\begin{array}{l}0.0354 \\
(0.008)\end{array}$} & \multirow[t]{2}{*}{2379} & \multirow[t]{2}{*}{$\begin{array}{l}0.9041 \\
(0.0070)\end{array}$} & \multirow[t]{2}{*}{2221} & \multirow[t]{2}{*}{316} \\
\hline SGD/JPY & $\begin{array}{l}0.0127 \\
(0.0097)\end{array}$ & $\begin{array}{l}0.9199 \\
(0.0436)\end{array}$ & $\begin{array}{l}0.0467 \\
(0.0219)\end{array}$ & $\begin{array}{l}0.1503 \\
(0.0774)\end{array}$ & & & & & & & \\
\hline
\end{tabular}

Notes: See notes to Table 2 . 